\title{
The Momentum \& Trend-Reversal as Temporal Market Anomalies
}

\author{
Vasiliki A. Basdekidou ${ }^{1}$ \\ ${ }^{1}$ SRFA Aristotle University of Thessaloniki, Greece \\ Correspondence: Vasiliki A. Basdekidou, Special Research Fund Account (ELKE), Aristotle University of \\ Thessaloniki, Greece. Tel: 30-697-277-5475. E-mail: Vasiliki.Basdekidou@ gmail.com
}

Received: January 6, 2017

Accepted: March 8, 2017

Online Published: April 5, 2017

doi:10.5539/ijef.v9n5p1

URL: https://doi.org/10.5539/ijef.v9n5p1

\begin{abstract}
The main goal of this paper is to introduce and discuss the temporal dimension and the subsequent (time-series) functionalities of two well-known technical market anomalies - the momentum anomaly and the trend-reversal anomaly. Our approach not only challenging the efficient-market hypothesis but also has a temporal dimension because it uses the "psychological time" at the beginning of a move, as a parameter in overnight post-market asset position trading strategies and daytime asset position strategies as well. Momentum and reversal have been documented extensively in financial literature and they are viewed, in the current paper, as temporal momentum and temporal trend-reversal anomalies because they are hard to fully explain within the standard static asset-pricing paradigm. A rational dynamic and temporal representative agent could explain and document better these anomalies and this is the case of this article. The presented research shows that momentum profit accumulates entirely overnight, while trend-reversal profit occurs entirely intraday. These findings reject classical theories of intraday and overnight returns. Hence, (i) a well designed overnight-position return strategy based on temporal momentum anomaly; and (ii) a well designed intraday-position return strategy based on temporal trend-reversal anomaly, could gain benefit at the expense of long-term investors and hedgers. After back-testing our research in available 16-year data, we found that overnight-position speculators profit from the proposed temporal momentum trading strategy approach at the expense of hedgers, and daytime swing traders profit from the proposed temporal trend-reversal trading strategy approach at the expense of long-term investors.
\end{abstract}

Keywords: market anomalies, momentum, trend reversal, temporal trading functionalities

\section{Introduction}

The main goal of this paper is to introduce and discuss the temporal (time-series) dimension and functionality of two well-known market anomalies -the Momentum Anomaly and the Trend-reversal Anomaly-challenging the efficient market hypotheses and relating to "time" during the overnight post-market and the daytime (intraday) sessions (Ang et al., 2006; Bali \& Cakici, 2008; Basdekidou, 2015; Basdekidou, 2016b). Momentum is the tendency of assets and trading instruments with good/bad recent performance to continue over-performing/under-performing in the near future (strong price action). On the other hand, reversal concerns predictability based on a recent performance history; so, assets and trading instruments that performed well/poor over a period tend to subsequently under-perform/over-perform for another period (swing price action). Closely related to reversal is the value effect, whereby the ratio of an asset's price relative to book value is negatively related to subsequent performance. Hence, in the current paper, these well-known anomalies have been reinforced in functionality and innovatively characterized and documented as temporal time-series market anomalies (Asness, 1994; Basdekidou, 2017a; Basdekidou, 2017b; Basdekidou \& Styliadou, 2017; Asness, Moskowitz, \& Pedersen, 2013).

As an application domain for the proposed (market anomaly) temporal functionality, we choose the SEC-approved (U.S. Securities and Exchange Commission; SEC.gov) category of leveraged "instruments" for mom-and-pop investors. Actually, these "instruments" are neither stocks nor mutual funds; they're just packaged products -of an underlined asset (e.g. crude oil WTI ETN, gold miners ETF)- using derivatives to create daily leverage. The introduced in this article temporal (time-series) momentum and trend-reversal trading strategy approaches have the ambition (i) to contradict as trading tools some of the most direct assessments and applied investigations of the well-known so-called "random walk hypothesis"; and (ii) to evaluate a number of outstanding behavioral, emotional and rational asset pricing theories (Asness, Moskowitz, \& Pedersen, 2016). Our findings present new evidence and challenges for those theories and for future research as well. 


\subsection{Problem Introduction}

Behavioral models of momentum were examined in detail by Asness (1994), Vayanos and Woolley (2013), and Campbell et al. (2014). On the other hand, no behavioral models related to trend-reversal are presented in corporate finance literature. In this domain, understanding symmetric and asymmetric information, fund flows, and cross-sectional variants in returns is critical for market and stock evaluation and trading purposes.

Trading is regarded as a temporal historical living system (Styliadis, 2007; Styliadis \& Vassilakopoulos, 2005) with a number of time-based anomalies challenging and contradicting the efficient-market hypothesis (EMH) and initiating relative trading functions. Anomalies in the markets appear on occasion and challenge the EMH. The EMH theory asserts that the current price of a security reflects all public and private information about that security. Thus, a "market" (e.g. a stock or 3x instrument) follows the path of a random walk hypothesis (RWH) (derived from a weak-form EMH), the premise of which states that current prices are not dependent on past prices and are normally distributed over time (Malkiel, 2003; Moskowitz, Ooi, \& Pedersen, 2012). According to EMH and RWH, changes in price are due to current news or events, which are impossible to predict in advance. The current article says that the EMH and RWH both ignore the realities of the markets (emotional factors), in that participants are not completely rational and that current price moves are not independent of previous moves.

Over the years, many studies have presented data about what academics call "market anomalies". Typically, for these anomalies, there are three common classifications: Fundamental, Technical, and Calendar-based anomalies. Also, there is another class of anomalies that simply could be referred to as "temporal" because of the time-series (timing) functionality involved. In this article we will discuss two of these "temporal" anomalies, called the temporal Momentum market anomaly and the temporal Trend-reversal market anomaly. These anomalies could be characterized as trading strategy approaches rather than as documented trading strategies; but if they parameterized by the time and particular by the overnight and intraday time periods, then they would respected as time-series temporal trading strategies. Historically, market anomalies display great timing-based trading functionalities, resulting in excellent return, profit, and wealth growth opportunities $(\mathrm{Ogden} \& \mathrm{Wu}, 2013$; Basdekidou, 2015). These temporal trading functionalities (e.g. the psychological time at the beginning of a move in trading according to Livermore (1940/2001) have not been fully documented yet. For instance, the observed mispricing in daytime and overnight trading sessions could be regarded as a temporal market anomaly offering a number of Temporal Trading Functionalities (TTF) (e.g. buy a bullish 3x instrument at the last 5 min before the closing bell - hold position overnight - sell this position next day during the morning session). The TTF characterized by embedded time-based behavioral biases dominant in securities, futures, Forex, and option markets (Basdekidou, 2016a; Basdekidou, 2016b; Basdekidou \& Styliadou, 2017; Basdekidou, 2017a; Basdekidou, 2017b).

The reason that long-term position investors (institutions) could buy overbought shares is the same, in regard also with Edelen, Ince, and Kadlec (2015), who provide evidence that long-term investors, traders and speculators prefer to purchase shares classified as overbought (momentum trading psychology) based on a number of classical equities-trading strategies ("trend-follow" trading), but without any TTF functionality in this case (Asness, Moskowitz, \& Pedersen, 2013; Ahn, Conrad, \& Dittmar, 2003). In trading strategies, these by default trading-passive position investors and the hedge funds are actually the trading "targets" of swing traders and speculators.

The current paper concludes that the swing traders profit from the proposed temporal trend-reversal approach at the expense of position investors; while the speculators profit from the proposed temporal (time series) momentum approach at the expense of hedgers. Asness (1994) and Moskowitz, Ooi, and Pedersen (2012) document significant "time-series momentum" in equity, options, currency, commodity, and futures for a number of liquid assets they consider. They, also, noticed the lack of any available TTF functionality and found persistence in returns for a one-year-period, which partially reverses over longer periods. These findings are consistent with sentiment theories of both, initial under-reaction and delayed over-reaction.

Lou et al. (2016) deliver remarkable new evidences about daytime and overnight returns, operated as time-series parameters to the proposed in our article temporal market anomalies. According to Lou et al. research, nearly $100 \%$ of the abnormal (i.e. market anomalies) returns on momentum strategies occur overnight. On the other hand, according to Asness, Moskowitz, and Pedersen (2013) the average intraday component of momentum profit is statistically insignificant. Their findings are subject to a number of controls and risk-adjustments (Ahn, Conrad, \& Dittmar, 2003). According to these papers, as well as to the findings of the current paper presented in Tables 1-7 (Section 3), the overnight return time-series parameter is bigger among large-cap stocks, 3x ETF/ETN instruments, and stocks with relatively large prices (Vayanos \& Woolley, 2013). 
The presented results, in Tables 1-7 (Section 3), are inconsistent with the simple classical theories and explanations about intraday and overnight trading return. Hence, this inconsistency could be characterized as a new (temporal) market anomaly not belonging to well-known fundamental, technical or calendar-based anomalies.

\subsection{The Temporal Momentum Anomaly: Return Rules}

The two trading rules, for the introduced temporal momentum return anomaly, are characterized as time-series related to position timing (overnight or intraday) and they are defined as follows:

The temporal Momentum Return Anomaly (tMRA) - The Overnight-position return rule (strategy):

On detecting a strong evening trend at the last $30 \mathrm{~min}$ of the daytime session (i.e. 3:30 - 4:00 pm EST)

Buy at the "Close" (i.e. during the last 5 min: 3:55 - 4:00 pm EST) of the current daily session

Hold position during the overnight period

Sell at the "Open" (i.e. during the first 30 min: 9:30 - 10:00 am EST) of next day's session

The temporal Momentum Return Anomaly (tMRA) - The Intraday-position rule (strategy):

On detecting a strong morning trend at the first $30 \mathrm{~min}$ of the daytime session (i.e. 9:30 - 10:00 am EST)

Buy at the "Open" (i.e. during the first 30 min: 9:30 - 10:00 am EST) of the current daily session

Hold position during the daily session

Sell at the "Close" (i.e. during the last 5 min: 3:55 - 4:00 pm EST) of the current daily session

\subsection{The Temporal Trend-reversal Anomaly: Return Rules}

Similarly, for the temporal trend-reversal market anomaly, the presented result is inconsistent with the simple classical theories and explanations about intraday and overnight trading return. Hence, this inconsistency could be characterized as a new market anomaly not belonging to well-known fundamental, technical or calendar-based anomalies.

The two rules for the introduced temporal trend-reversal return anomaly, are characterized as time-series related to position timing (overnight or intraday) and they are defined as follows using, with a [10-min] time-frame, the Parabolic SAR technical momentum indicator represented as a string of "dots" above or below the price action's candlestick or Heikin-Ashi representation bars (Wilder, 1978):

The Trend-reversal Return Anomaly (TRA) - The Overnight-position return rule (strategy):

On detecting a strong intraday trend-reversal between 10:00 am EST and 3:00 pm EST

Buy at Parabolic SaR dot-string reverse (i.e. above $\rightarrow$ below) during the current session

Hold position overnight

Sell at Parabolic SaR dot-string reverse (i.e. below $\rightarrow$ above) during a next day's session

The Trend-reversal Return Anomaly (MRA) - The Intraday-position return rule (strategy):

On detecting a strong intraday trend-reversal between 10:00 am and 3:00 pm EST

Buy at Parabolic SaR dot-string reverse (i.e. above $\rightarrow$ below) during the current session

Hold position during the current session only

Sell at Parabolic SaR dot-string reverse (i.e. below $\rightarrow$ above) anytime during the session or at close

The above four (4) trading rules were following strictly in the back-testing procedure (1/1/2010-30/6/2016 data) for producing the statistical information presented in Tables 1-7 (Section 3).

\subsection{The Daytime vs. Overnight Returns Comparative TTF}

In the situation of equities and non-equities "timing" (stocks, options, Forex, etc.), Cesari, Espenlaub, Khurshed, and Simkovic (2012) just argues on the effects of share-holding and stock liquidation on the timing transactions in open and close position executive orders, but no more details for long-term, short-term or daily TTF functionalities (e.g. a low-risk TTF functionality - the "psychological time" at the beginning of an intraday move) were given.

Even more, their approaches in timing transactions, are based on a 3-year period which is regarded as too big, even for the "buy-and-hold" investors, for nowadays internet-based swing and volatile securities markets traded on a daily bases (e.g. leveraged ETF; Gold, Silver, WTI Oil, and Natural Gas ETN). 
In Skyba (2012), the author concludes that both, the daytime and overnight returns, are persistent with the control acting of long-term passive-trading investors. Also, in Skyba's article no TTF functionalities were discussed. Furthermore, Hao (2014) states that companies with higher short-term non-commercial shareowners (i.e. speculators) enjoy more negative atypical results at the report release timing (intraday trading) and concludes that momentary corporate shareowners and speculators are not prompted to risk their capital and profit in overnight positions (a risky TTF functionality).

The daytime versus overnight returns could be characterized as a comparative TTF and can be studied by analyzing the differences in returns between strategies based on trading positions holding: (i) during the day's session (defined herein as regular NYSE trading hours: 9:30 am - 4:00 pm EST); and (ii) the overnight period. In the current article, for back-testing purposes of both returns, we use the trade data of the SPDR S\&P 500 ETF (SPY), from January 1, 2000 to June 30, 2016. For this comparative TTF we define the daytime return as the difference in pricing between the day's open and the day's close; and the overnight return as the difference between the day's close and the following morning's open (Nguyen \& Tran, 2016).

\subsection{Motivation and Previous Literature}

The current article is relevant to some other articles that investigate corporate share-holding under the prism of the trading timing. In this frame, some articles (Markoulis \& Neofytou, 2016; Moskowitz, Ooi, \& Pedersen, 2012) targeted on the information asset and stock-taking intelligence of corporate investors, while others (Hao, 2014; Baker, Stein, \& Wurgler, 2003) targeted the trading strategies and plans, but in both cases no TTF information was given. Gibson, Safieddine, and Sonti (2004) report that seasoned equity and option initiatives, with the bigger boost in corporate share-holding, are detected between the (relative to "timing") quarters -1 and +1 and qualify this outperform to their competitive convenience asset position.

Chemmanur, He, and $\mathrm{Hu}$ (2009) find that long-term passive-trading investors (as opposed to non-commercial short-term investors and traders) are likely to experience bigger share positions in SEOs hoping on better results (profit) and their transactions somewhat greatly exceed a (even a well designed) passive "buy-and-hold" trading plan by the share-holding investors (Asness, Moskowitz, \& Pedersen, 2013; Nguyen \& Tran, 2016; Basdekidou \& Styliadou, 2017).

In classical financial literature, Jegadeesh and Titman (1993), and Moskowitz, Ooi, and Pedersen (2012), document momentum for individual U.S. stocks, predicting returns over horizons of 3-12 months by returns over the past 3-12 months. De Bondt and Thaler (1985) document reversal, predicting returns over horizons of up to 5 years by returns over the past 3-5 years. In accordance to the above articles, Edelen, Ince, and Kadlec (2015), examined corporate trading and securities return divergences, and discovered that corporate firms just prefer to purchase shares categorized as overbought (Basdekidou, 2016a).

In opposition to the above articles that do not incorporate TTF and spotlight mainly on whether long-term investors and old-shareowners are better-informed (i.e. insiders functionality), the current research article targets on the dominant emotional functionality and the underlined trading TTF functionalities in short-term trading.

Alti and Sulaeman (2012) also expressed a disagreement to these articles, by pointing out how the IPO trading is time-influenced. Also, in their paper, they support the position that the IPO trading returns are connected with a pre-issue corporate investor demand at the appropriate timing. The Alti and Sulaeman's IPO dependable approach has had a timing dimension but it is not generic, as they use the corporate investor temporal demand as a gauge of the market's interest in the company's equity initiative. This temporal demand could be regarded as a TTF but no more details were given. Finally, Kang, Ratti, and Vespignani (2016), Lee and Ni (2002), and Kilian (2009) investigate the role of oil production in daytime crude oil (WTI) CfD trading and discuss the impact of oil prices shocks on the markets. Also, in these articles, the temporal dimension of oil's price action momentum or trend-reversal functionality is not discussed.

Finally, the link between temporal (time series) momentum returns and the positions of speculators and hedgers indicates that speculators profit from time series momentum trading strategies at the expense of hedgers. This evidence is consistent with speculators earning a premium via time-series momentum for providing liquidity to hedgers. Decomposing futures returns into the effect of price changes, which captures information diffusion, and the roll return, which captures how hedging pressure affects the shape of the futures curve, we find that shocks to both price changes and roll returns are associated with time series momentum profits. However, only shocks to price changes partially reverse, consistent with behavioral theories of delayed over-reaction to information, and not hedging pressure (Moskowitz, Ooi, \& Pedersen, 2012; Edelen, Ince, \& Kadlec, 2015).

In this domain, the main target of the current article is disparate. Actually, we investigate whether the overnight 
shareowners (as momentary speculators) profit from the application of the overnight holding TTF, as a time parameter, to both trading approaches introduced in this paper as temporal market anomalies. It is notable that, the results obtained does depend on the trading instrument (3x leveraged ETF/ETN; index-based ETF; etc.) and therefore always an adaptive personalized functionality is involved ("volatility" in case of the trading instrument and "user profile" for the case of the investors, traders, and momentary speculators).

\subsection{Paper's Structure}

The rest of the article is organized as follows: In Section 2 ("Importance: Momentum \& Trend-reversal Temporal Anomalies") the importance of the momentum and trend-reversal approaches is introduced and demonstrated by nine (9) Figures. In Section 3 (“Analysis: The Momentum \& Trend-reversal Temporal Market Anomalies") the innovative terms temporal Momentum market anomaly and temporal Trend-reversal market anomaly are defined, analyzed and documented by back-testing, in seven (7) Tables, their performance in daytime-position and overnight-position return trading strategies. Finally, Section 4 ("Conclusions \& Discussion") summarizes the conclusions and discusses paper's innovations and contributions.

\section{Importance: Momentum \& Trend-Reversal Temporal Anomalies}

In this Section the magnitude of momentum and trend-reversal, as a value effect that these anomalies generate, is introduced and defined. In corporate finance, the magnitude of the value effect is typically measured through the performance of trading strategies. So, we first construct a measure of performance and then compute it in a calibration of the proposed model (Livermore, 1940/2001; Lefèvre, 1923/2010).

Consider an anomaly-based trading strategy consisting of a portfolio of vector of weights $\mathrm{w}_{\mathrm{t}} \equiv\left(\mathrm{w}_{1 \mathrm{t}}, . ., \mathrm{w}_{\mathrm{Nt}}\right)$, where $\mathrm{w}_{\mathrm{nt}}$ is the number of shares invested in a risky asset $n$ at time $t$. In our portfolio there are $\mathrm{N}$ risky assets (stocks, leveraged ETF/ETN, futures, options, etc.). Time $t$ is continuous and goes from 0 to infinity. Part of the strategy expected return is compensation for bearing risk that correlates with the underlined market index (in our case the portfolio). We focus on the remainder by index-adjusting the strategy, i.e., combining it with a position in the index such that the covariance between the overall position and the index is zero.

The index-adjusted strategy is driven by purely cash flows and is equal to its symmetric-information counterpart (Vayanos \& Woolley, 2013). Note that the position in the index can be time-varying, reflecting possible time-variation in the covariance between the anomaly-based trading strategy and the index. We measure the anomaly performance of the strategy $\left(\mathrm{A}_{\mathrm{p}}\right)$ by the Sharpe Ratio of its index (portfolio)-adjusted version of the vector of weights $\left(\hat{\mathrm{w}}_{\mathrm{t}}\right)$.

$$
\hat{w}_{t} \equiv w_{t}-\left(\operatorname{Cov}_{t}\left(w_{t} d R_{t}, n d R_{t}\right) / \operatorname{Var}_{t}\left(n d R_{t}\right)\right) * n
$$

where: $\mathrm{w}_{\mathrm{t}} \mathrm{dR}_{\mathrm{t}}$ is the daily return of the portfolio $\mathrm{w}_{\mathrm{t}}$ at time $t ; n \mathrm{dR}_{\mathrm{t}}$ is the daily return of the asset $n$ at time $t$; and $\operatorname{Cov}_{\mathrm{t}}\left(\mathrm{w}_{\mathrm{t}} \mathrm{dR}_{\mathrm{t}}, \mathrm{ndR}_{\mathrm{t}}\right)$ is the covariance between portfolio and asset returns at time $t$.

The Sharpe Ratio is the ratio of expected excess return to standard deviation.

$$
\text { Anomaly strategy performance }\left(A_{p}\right) \equiv \operatorname{Sharpe} \operatorname{Ratio}\left(\hat{\mathrm{w}}_{\mathrm{t}}\right)
$$

Sharpe Ratio $\left(\hat{\mathrm{w}}_{\mathrm{t}}\right) \equiv$ Ratio (expected excess returns / std dev).

The main difference between intraday (daytime: 09:30 am - 04:00 pm EST) and overnight periods is that much of the overnight-position return has earnings announcements functionality (at least for the USA stock markets) and therefore may reflect information surprises. Nearly a $25 \%$ of these overnight earnings announcements published in the first 30 min after market close; while the $60 \%$ published in the morning before market opening.

According to our review of the 2010-2016 data, companies tend to submit important regulatory filings just after market closing. Barclay and Hendershott (2003) find that though price action is more active and efficient during the intraday period, after-hours trading contain more information and support greater trading functionality than the daytime trading. Also, according to our research with the pre-open auctions on the NYSE and NYSE Arca, the same conclusions were documented (Moskowitz, Ooi, \& Pedersen, 2012).

For the current paper, the profit/losses trading data (2010-2016), for the UWTI 3x leveraged Exchange-Traded Note (ETN) (VelocityShares, 2017) and the S\&P 500 SPY 1x leveraged Exchange-Traded Fund (ETF) (Direxion Investments, 2017), came from many resources. The Barron's information databases and sources, a Wall Street Journal affiliate (Barron's, 2016); the StockCharts.com initiative; the Securities \& Exchange Commission/SEC notices, releases \& announcements; the Commitments of Traders (CoT) / CFTC speculative net positions reports for speculator net length and open interest data; the Yahoo! Finance insiders data feed; the SEC EDGAR database; the Zacks.com; and the Thomson Financial corporate holdings database (Basdekidou, 2017a). 
The proposed volatility-strategy and volatility-tactical can be used in concert with stocks, leveraged instruments, ETFs, ETNs, swaps, futures, and/or options to implement risk management strategies and it is dedicated to providing individual traders and institutional investors with sophisticated solutions for portfolio and trading risk management: (i) reward to risk ratios; and (ii) stop-loss and stop-profit sell orders. The proposal's success results from delivering innovative, efficient, and intelligent functionality for a wide range of intraday traders and institutional investors (Asness, 1994; Asness, Moskowitz, \& Pedersen, 2016).

In this paper, the above numbers were used to estimate, with an acceptable standard deviation (std. dev.), total corporate securities profit / loss and position changes (if applicable) and for a period from January $1^{\text {st }}, 2010$ to June $30^{\text {th }}$ 2016. So, for each of the above thirteen (13) semesters, the trades involved parameterized as overnight and daytime returns for: (i) the (American) crude oil CfD projected as UWTI 3x leveraged ETN (VelocityShares, 2017); and (ii) the Standard \& Poors 500 SPY 1x leveraged ETF (Direxion Investments, 2016), and categorized as profit or loses in following Figures 1 and 2.

The result is an unbalanced panel, covering the sample time period from January $1^{\text {st }}$ (2010) to June $30^{\text {th }}$ (2016), with more than 9,000 observations annually used in the back-testing procedure. The presentation equity curve, in Figures 1-5, incorporates the standard deviation for a quality interpretation of the both trading approaches introduced in this article (temporal Momentum Anomaly and temporal Trend-reversal Anomaly) and projected for overnight-position and daytime-position return strategies.

\subsection{The Vector Auto-Regression Results (VAR)}

According to Moskowitz, Ooi, and Pedersen (2012) time-series momentum is not purely driven by just one component of futures returns. Both, the spot return change and the roll yield provide predictive power for futures returns. In their paper they conclude that, as the vector auto-regression (VAR) results show in the following three figures, there is an interesting dynamic correlation between time-series momentum, hedging positions and the CoT / CFTC speculative net positions reports (Figures 1, 2, \& 3).

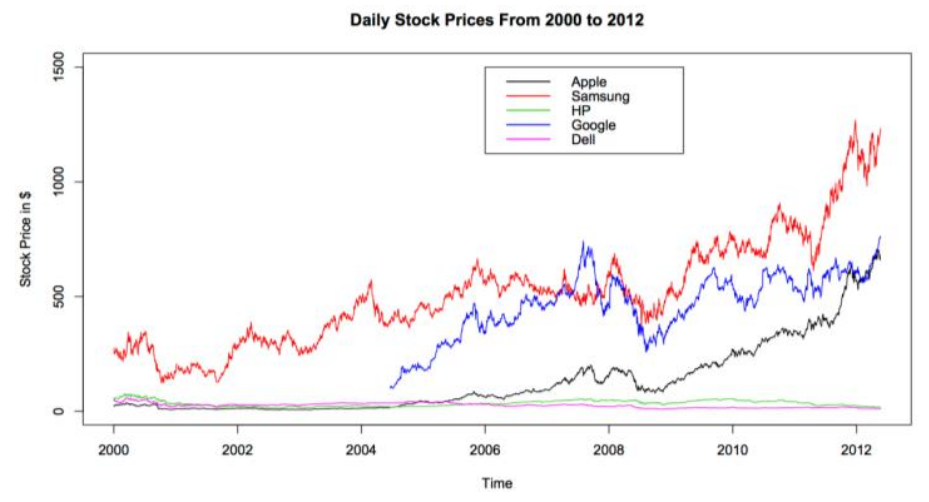

Figure 1. Vector auto-regression (VAR) results - Daily stock prices from 2000 to 2012

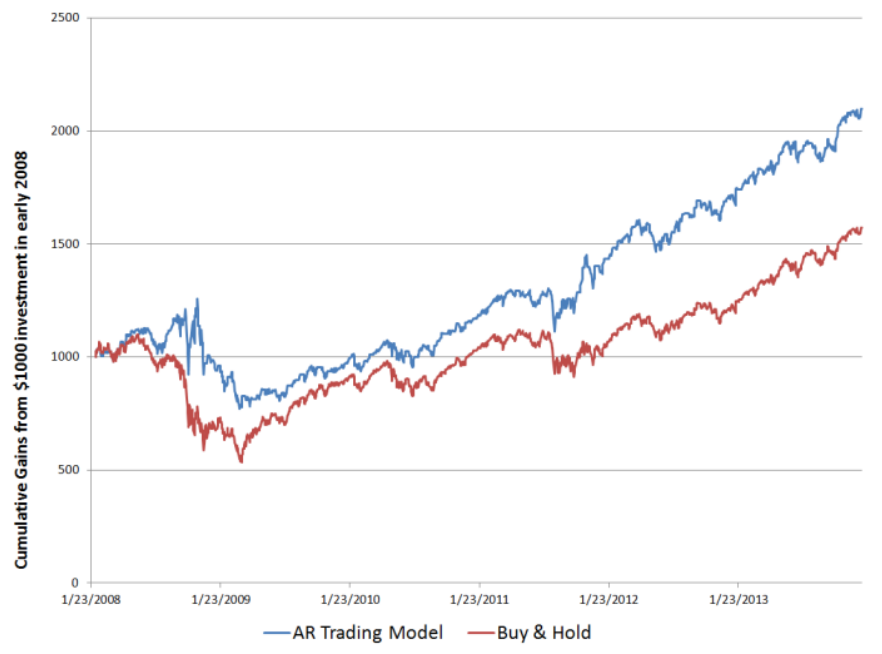

Figure 2. Vector auto-regression (VAR) results - AR trading model vs. Buy \& Hold from 2008 to 2014 


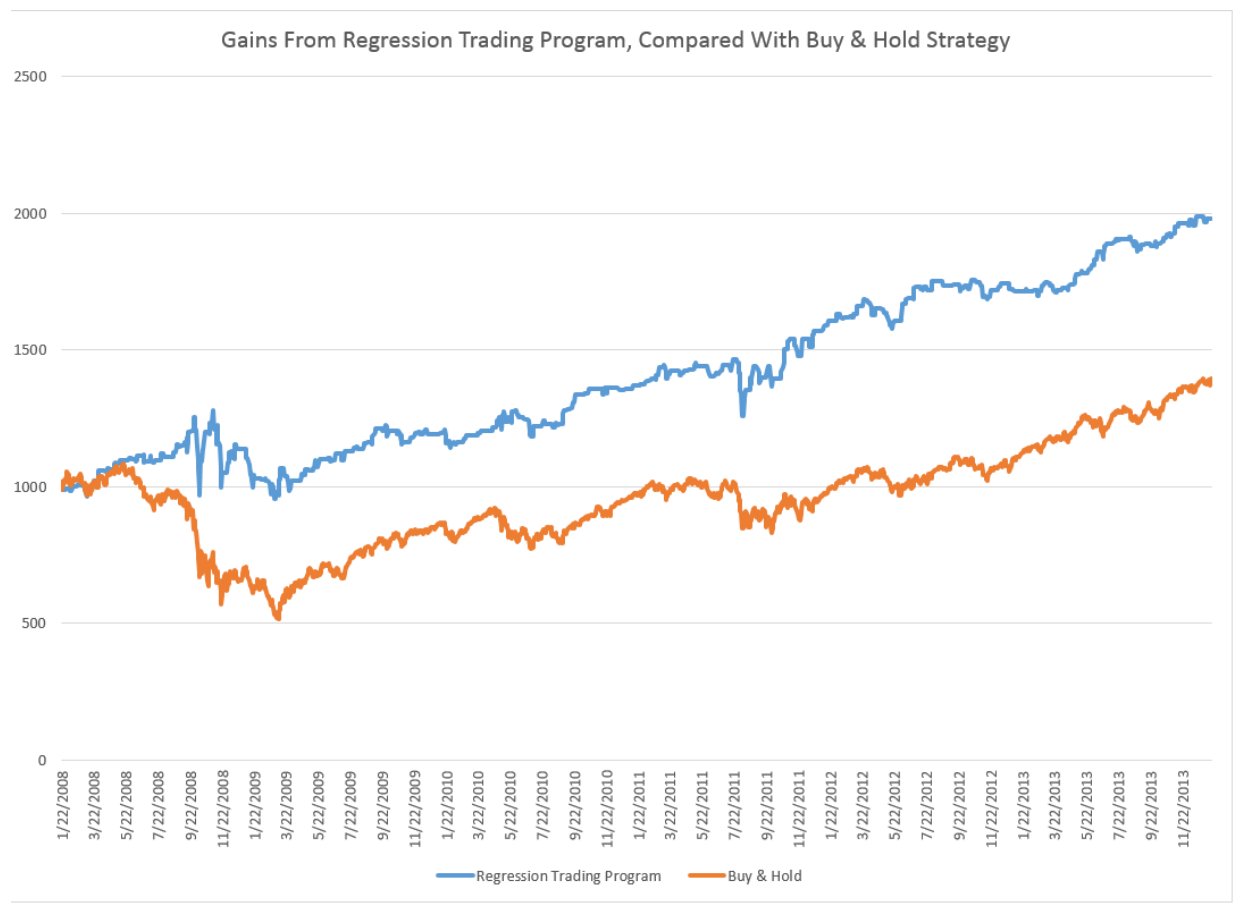

Figure 3. Vector auto-regression (VAR) results - Regression trading program vs. Buy \& Hold from 2008 to 2013

In the current paper, as the Figures 4 and 5 indicate (next page), we confirm (by using a VAR to $3 x$ ETN UWTI) that speculators trade, using overnight-position return strategies, in the same direction as the dominant trend of the ETN and reduce their positions as the trend reverses; whereas hedgers take the opposite side of these trades. In addition, as the VAR results and the CoT / CFTC reports show, there is an interesting dynamic between time-series momentum and the net speculator and hedging daytime and overnight positions.

So, speculators seem to ride the trend for about a year, eventually reducing their positions and taking the opposite side before it reverses. In this process, they earn positive excess returns always at the expense of hedgers, who may be willing to compensate speculators for liquidity provision in order to maintain their hedge.

It is a common misinterpretation between the market participants (retail traders and institutions as well) that the majority of returns from day-to-day trading are extracted from the daytime session, rather than from the overnight period. This would make sense, as in real life more people track in mind the daytime activities as opposed to the overnight price action trading. But, as Figures 4 and 5 indicate (next page), the opposite is true of overnight vs. daytime returns. Obviously, this is a strong emotional relation to both daytime-position and overnight-position return strategies based on timing, money risk management (exit policy) and emotional control (Livermore, 1940/2001; Lefèvre, 1923/2010).

According to our research, we find a significant time-series "temporal momentum effect" that is remarkably consistent across the nearly twenty dozen futures CfD contracts and several major asset classes we study for the 3x ETN UWTI over the last 16 years (1/1/2010-30/6/2016) (Figures 4, \& 5). This time-series temporal momentum effect is distinct from cross-sectional momentum (Asness, Moskowitz, \& Pedersen, 2013), though the underlined two momentum functionalities are related.

Decomposing both time-series and cross-sectional momentum profits, we find that the dominant force to both strategies discussed in this paper in relation to temporal momentum and temporal trend-reversal anomalies (i.e. the daytime-position return strategy and the overnight-position return strategy) has a significant positive correlation coefficient to security's excess temporal momentum anomaly and it's lagged temporal trend-reversal anomaly.

This evidence is consistent with initial under-reaction stories, but may also be consistent with delayed over-reaction theories of money risk management, and sentiment (emotional) control (Livermore, 1940/2001; Lefèvre, 1923/2010) as the time-series momentum effect partially reverses after one semester (or year) to the next semester (or year) (Moskowitz, Ooi, \& Pedersen, 2012). 
2.2 The Temporal Momentum Anomaly Proposed Trading Approach (Overnight-Position Return): Exchange-Traded Note (3x ETN) Curve Detailed - UWTI Daily (01/01/2010 - 30/06/2016; 16:00 - 09:30)

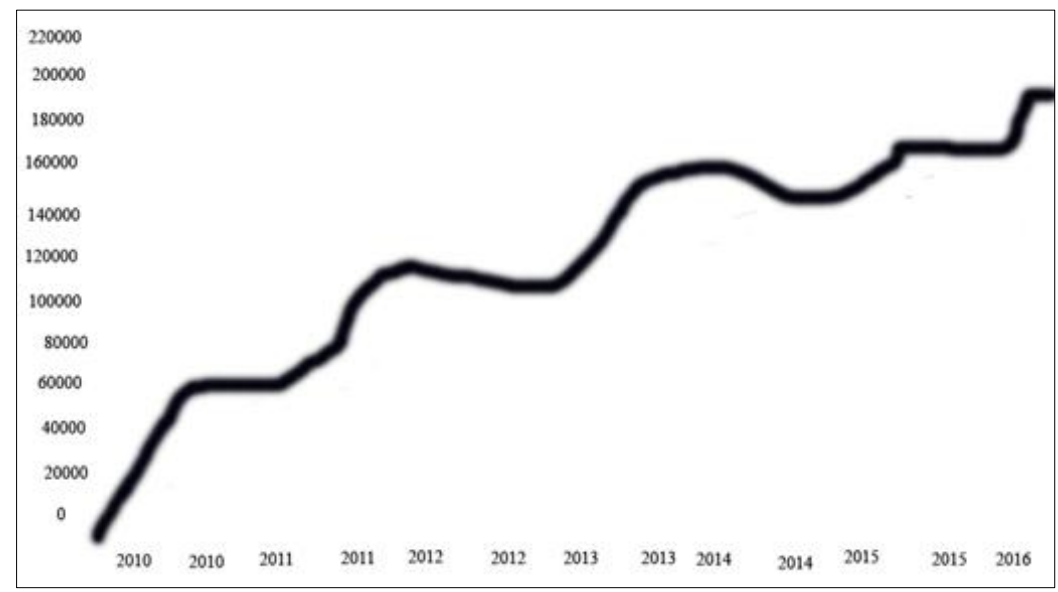

Figure 4. UWTI 3x ETN, from 1/1/2010 to 30/06/2016

Note. The equity curve of overnight-position return (today's open - yesterday's close) of $\$ 100,000$ invested per trade is displayed. Transactions don't include commission or slippage costs.

2.3 The Temporal Momentum Anomaly Proposed Trading Approach (Daytime-Position Return): Exchange-Traded Note (3x ETN) Curve Detailed - UWTI Daily (01/01/2010 - 30/06/2016; 09:30 - 16:00)

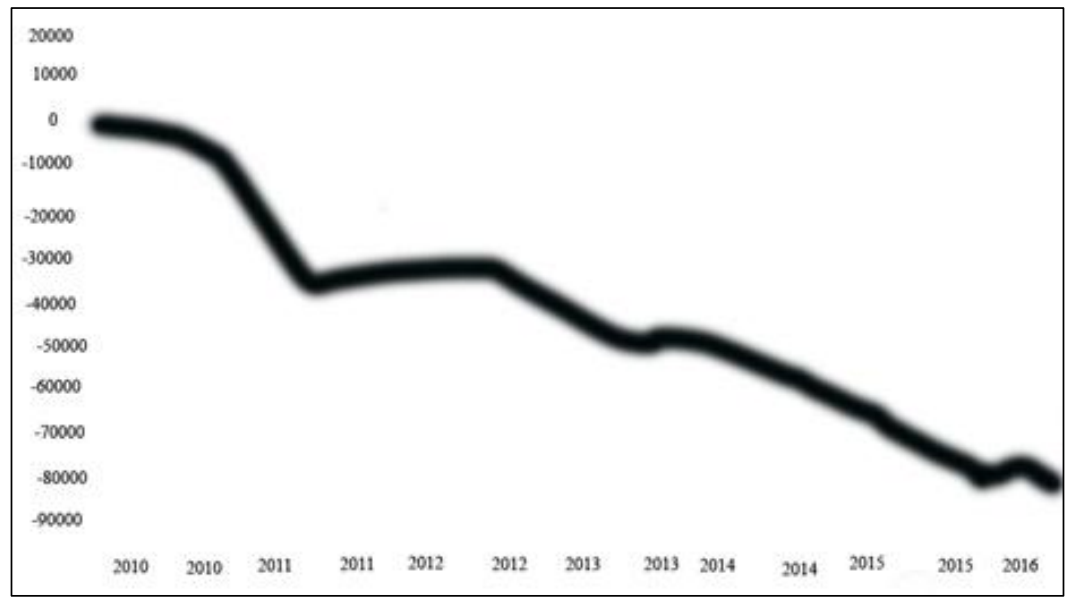

Figure 5. UWTI 3x ETN, from 1/1/2010 to 30/06/2016

Note. The equity curve of daytime-position return (close - open) of $\$ 100,000$ invested/trade is displayed. Transactions don’t include commission or slippage costs.

According to literature time-series momentum exhibits strong and consistent performance across many diverse asset classes, has small loadings on standard risk factors, and performs well in extreme periods, all of which present a challenge to the random walk hypothesis and to standard rational pricing models (Moskowitz, Ooi, \& Pedersen, 2012).

The evidence also presents a challenge to current behavioral theories (regarding trading psychology, psychological time, money management, risk management, and emotional control) since the leveraged ETF/ETN markets we study vary widely in terms of the type of investors, traders and speculators (retail, institutions; intraday, swing, long-term), yet the pattern of returns remains remarkably consistent across these markets and is highly correlated across very different asset classes (Asness, Moskowitz, \& Pedersen, 2013; Nguyen \& Tran, 2016; Basdekidou \& Styliadou, 2017; Livermore, 1940/2001; Lefèvre, 1923/2010; Moskowitz, Ooi, \& Pedersen, 2012).

Indeed, the correlation coefficient among time-series temporal momentum for daytime-position and 
overnight-position returns, is stronger than the correlation coefficient among time-series temporal trend-reversal (passive long positions) for daytime-position and overnight-position returns, across the same asset (stocks, options, futures) and leveraged instrument classes; implying the existence of a common component to time-series temporal momentum with great trading and profit (return) functionality that is not present in the underlying assets and leveraged instruments themselves (Vayanos \& Woolley, 2013; Asness, Moskowitz, \& Pedersen, 2016; Asness, 1994; Basdekidou, 2017a; Livermore, 1940/2001; Lefèvre, 1923/2010; Moskowitz, Ooi, \& Pedersen, 2012).

Following, Figure 6 (overnight-position return for the SPY 1x ETF) and Figure 7 (daytime-position return for the SPY 1x ETF) display the equity curve detailed for the SPY daily and for the period 02/02/1993 - 15/06/2011 (Skyba, 2012; Basdekidou, 2017b; Livermore, 1940/2001; Lefèvre, 1923/2010; Moskowitz, Ooi, \& Pedersen, 2012).

2.4 The Temporal Trend-Reversal Anomaly Proposed Trading Approach (Overnight-Position Return): Exchange-Traded Fund (1x ETF) Curve Detailed - SPDR S\&P 500 SPY Daily (02/02/1993 - 15/06/2011; 16:00 $-09: 30)$

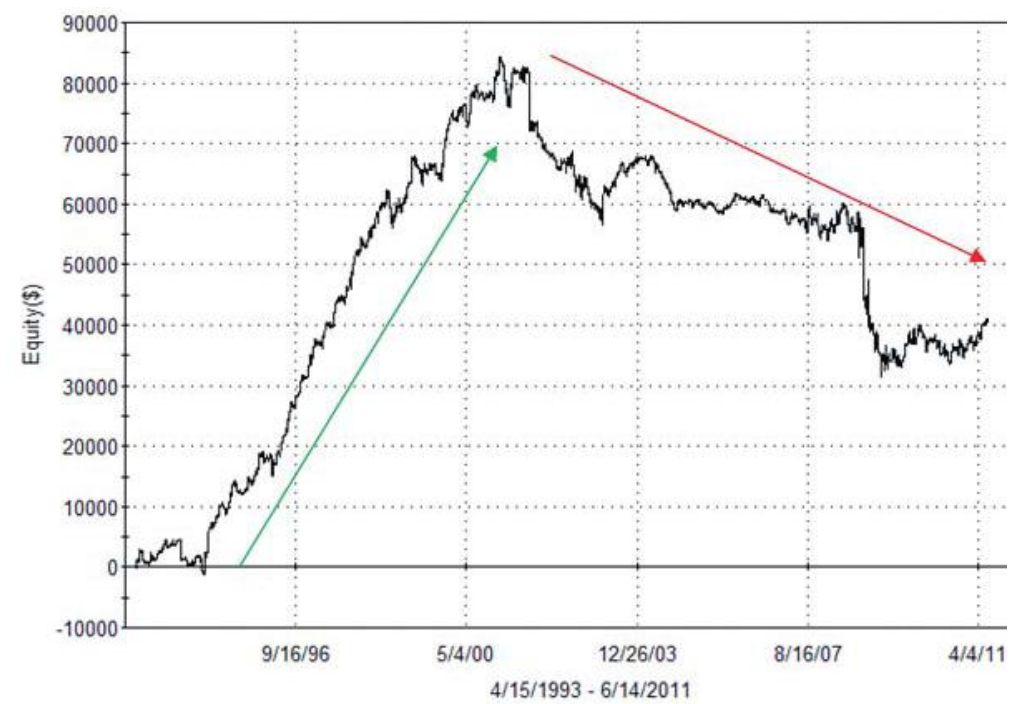

Figure 6. SPDR S\&P 500, SPY 1x ETF, from 2/2/1993 to 15/6/2011

Note. The equity curve of overnight-position return (today's open - yesterday's close) of $\$ 100,000$ invested per trade is displayed. Transactions don't include commission or slippage costs.

2.5 The Temporal Trend-reversal Anomaly (Intraday-Position Return): Exchange-Traded Fund (1x ETF) Curve Detailed - SPDR S\&P 500 SPY Daily (02/02/1993 - 15/06/2011; 09:30 - 16:00)

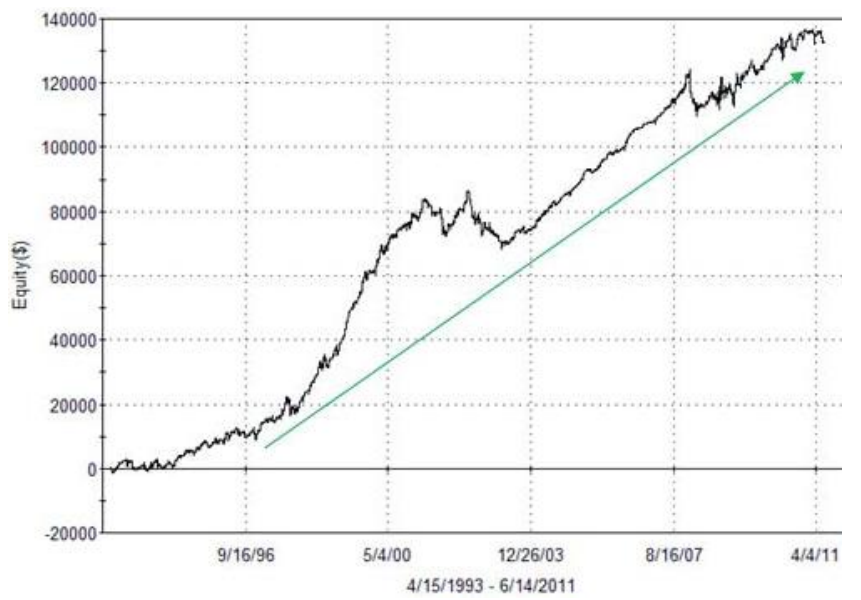

Figure 7. SPDR S\&P 500, SPY 1x ETF, from 2/2/1993 to 15/06/2011

Note. The equity curve of daytime return (close - open) of $\$ 100,000$ invested/trade is displayed. Transactions don't include commission or slippage costs. 


\subsection{Typical Examples of Overnight-position \& Daytime-Position Return Strategies}

In Figure 8, a typical example of an overnight-position return strategy, parameterized within the temporal Momentum Market Anomaly, is displayed. In this Figure we can see the stock BSE: Sensex with a low price of 22,494 on February $29^{\text {th }}, 2016$ and on September $30^{\text {th }}, 2016$ the same stock with a high of 29,000 (i.e. $28.9 \%$ return).

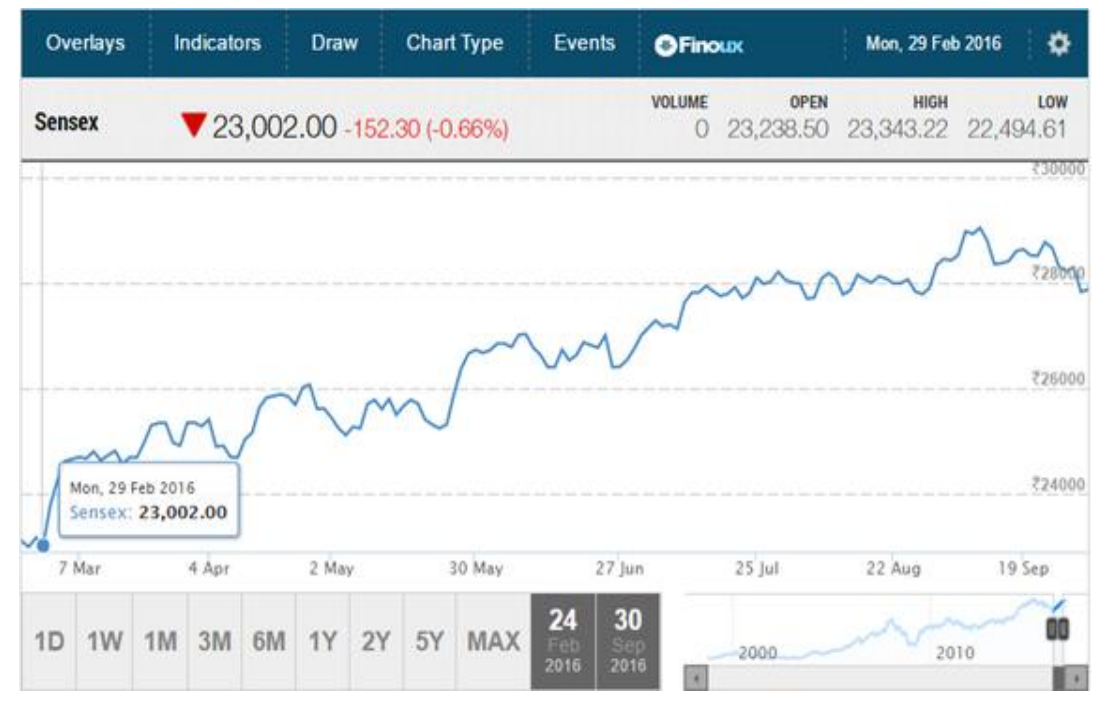

Figure 8. The temporal momentum anomaly - overnight-position return strategy

Note. The equity curve for the stock BSE, INDEXBOM: Sensex is displayed (from 29/2/2016 to 30/09/2016)

In Figure 9, a typical example of an intraday-position return strategy, parameterized within the temporal Trend-reversal Market Anomaly, is displayed. In this Figure we can see the stock NSE: Nifty Bank performed better compared to the stock Sensex (Figure 8). So, on February $25^{\text {th }}$, 2016, Nifty Bank recorded a low of 13,519 and on September $7^{\text {th }}, 2016$ recorded a high of 20,406 . That is to say, a return of $50.9 \%$ in 6 months! For the performance related to these examples (Figures $8, \& 9$ ), the commission and/or slippage costs is not included.

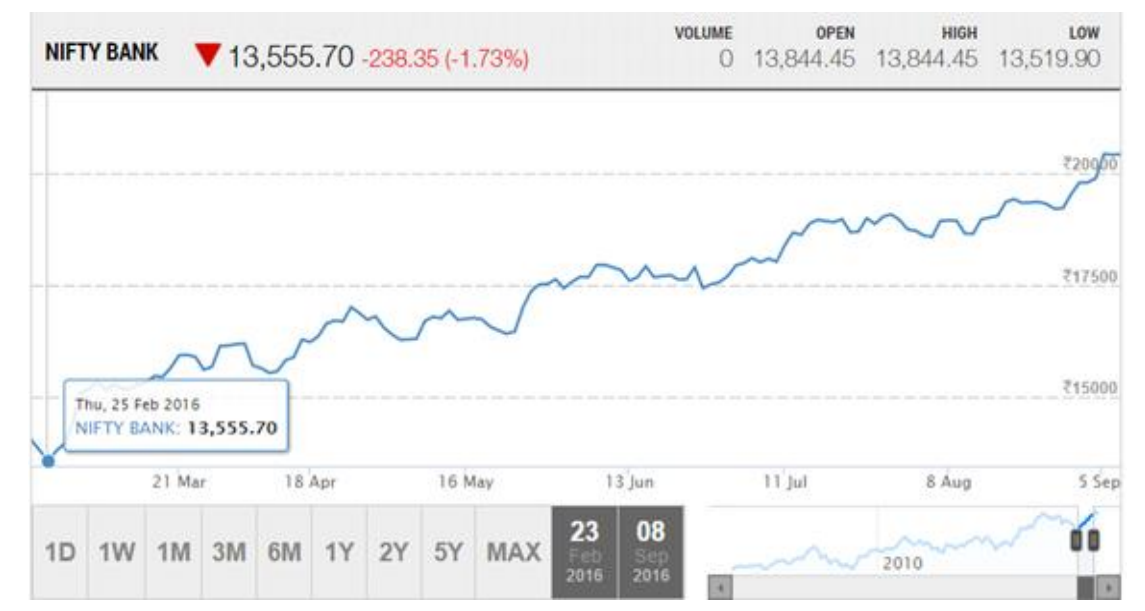

Figure 9. The temporal Trend-reversal Anomaly - Intraday-position return strategy

Note. The equity curve for the stock NSE: NIFTY BANK is displayed (from 25/2/2016 to 30/09/2016)

\section{Analysis: The Momentum \& Trend-Reversal Temporal Market Anomalies}

In this Section, the innovative terms temporal Momentum and temporal Trend-reversal market anomalies are defined, analyzed and documented. So, the temporal Momentum market anomaly is defined as a two-dimension array of TTF functionalities applied in daytime (intraday) trading for any tradable asset. In this definition, the first dimension is the "psychological time" at the begging of a move, while the other dimension is the price action patterns like gaps ("windows" in technical analysis terminology) and breakouts (Livermore 1940/2001). 
Similarly, the temporal Trend-reversal market anomaly is defined as a two-dimension array of TTF functionalities applied in swing trading for any tradable asset regarding: (a) Price action consolidation patterns, like: uprising/declined triangles, rising/falling wedges, and cups with Handle; (b) Resistance and support zones, like: trend-lines, H\&S-necklines, moving averages (e.g. EMA(200)); and (c) Price action vs. technical indicators (like MACD and RSI) divergences. Also, in this definition, the first dimension is the "psychological time" at the begging of a move, while the other dimension is the above three technical analysis formations, i.e. consolidation-patterns, resistance and support zones, and divergences (Lefèvre, 1923/2010).

For the proposed two momentum market anomalies, these TTF are operated as short- and long-term functionalities parameterized by popular price action time-frames (e.g. [3-minute], [10-minute], and [30-minute] for the Momentum anomaly and [1-hour], [2-hour], and [daily] for the Trend-reversal anomaly); and they could be documented by time- and profit-targets in trading any asset as follows: (i) define intraday momentum trading strategies by specific time- and profit-targets; and open/close long/short positions at a specific time- and profit-target; and (ii) define swing trend-reversal strategies by consolidation price action patterns, resistance and support zones, and price action / technical indicators divergences.

The TTF temporal functionalities operate as great warning dynamics trading signals (w!D signals) when they are related to particular candlestick and price action pattern-targets. For the proposed trading strategies, these short-term pattern-targets operate as psychological time TTF w!D signals awaiting the final confirmation/triggering signal (e.g. volume increase; candlestick break; Jesse Livermore's resistance pivotal-line breakout; Jesse Livermore's support pivotal-line breakdown) just before the executive order (i.e. open / close position) (Wilders, 1978; Campbell et al., 2014; Livermore 1940/2001).

\subsection{The temporal Momentum versus Temporal Trend-Reversal Returns}

The relation temporal Momentum Return vs. temporal Trend-reversal Return is defined by analyzing the differences in returns between the underlined two innovative temporal anomalies discussed in this paper. For volatility-strategy and volatility-tactical purposes, a backtest procedure has been applied on both, a 3x ETN instrument (UWTI) and a 1x ETF instrument (SPY). This procedure has generated for these two instruments 4,820 and 4,624 trades respectively (Tables 1-4). Individual trades contain more information and trading TTF functionality after-hours (overnight) than during the daily session (intraday: 09:30 am - 04:00 pm EST). Hence, because the information asymmetry declines over the intraday trading hours, price changes are larger, reflect more private information and trading functionality, and they are less noisy before the open than after the bell-clock.

Following Table 1 is referred to the introduced temporal Momentum Anomaly and presents, in summary, the annual return (\%) after the application of the backtest procedure to the $3 \mathrm{x}$ instrument UWTI, for the period: $1^{\text {st }}$ January $2010-30^{\text {th }}$ June 2016 (4,820 trades generated). For statistical documentation and research purposes, the returns were time-projected in two categories and they characterized as overnight-position and daytime (intraday)-position returns. In this frame, the UWTI has an annual overnight return of $7.88 \%$, while the annual daytime return is $-5.13 \%$.

Additionally, a quality analysis, based on the recorded standard deviation values, says that -surprisingly- an overnight-position return trading strategy (in the case of a temporal Momentum Anomaly) is less risky than a daytime-position return strategy, because of the lower annual standard deviation and greater Sharpe ratio values recorded in overnight-position returns. This is why the statistical quality indicator Sharpe Ratio (which does not include in calculations the risk-free interest rate) for the overnight-position temporal Momentum Anomaly strategy is 0.92 , compared to the -0.28 of the daytime-position temporal Momentum Anomaly strategy.

Table 1. Temporal momentum anomaly: UWTI 3x leveraged ETN: Annual Returns (\%) from a backtesting procedure $(4,820$ trades $)$

\begin{tabular}{ccccc}
\hline & \multicolumn{4}{c}{ Trading Results (\%) } \\
\cline { 2 - 5 } & Annual Return & Annual std. dev. & Sharpe Ratio & Total Return \\
\hline Overnight-position Return Strategy & $7.88 \%$ & $11.32 \%$ & 0.92 & $130.42 \%$ \\
Daytime-position Return Strategy & $-5.13 \%$ & $17.37 \%$ & -0.28 & $-67.31 \%$ \\
\hline
\end{tabular}

Similarly, Table 2 refers to the introduced temporal Trend-reversal Anomaly and presents, in summary, the annual return (\%) after the application of the backtest procedure to the $1 \mathrm{x}$ instrument SPY, for the period: $1^{\text {st }}$ January 2010 - 30 $0^{\text {th }}$ June 2016 (4,624 trades generated) (Skyba, 2012). For statistical documentation and 
research purposes, the returns were time-projected in two categories and they characterized as overnight-position and daytime (intraday)-position returns. In this frame, the SPY has an annual overnight return of $-8.65 \%$, while the annual daytime return is 4.09\% (Hao, 2014; Baker, Stein, \& Wurgler, 2003; Nguyen \& Tran, 2016; Lee \& Ni, 2002; Kilian, 2009).

Additionally, a quality analysis, based on the recorded standard deviation values, says that a daytime-position return trading strategy (in the case of a temporal Trend-reversal Anomaly) is less risky than an overnight-position return strategy, because of the lower annual standard deviation and greater Sharpe ratio values recorded in daytime-position returns. This is why the statistical quality indicator Sharpe Ratio (which does not include in calculations the risk-free interest rate) for the daytime-position temporal Trend-reversal Anomaly strategy is 0.91, compared to the -0.21 of the overnight-position temporal Trend-reversal Anomaly strategy (Campbell et al., 2014).

Table 2. Temporal trend-reversal anomaly: SPDR S\&P 500 SPY 1x leveraged ETF: Annual Returns (\%) from a backtesting procedure $(4,624$ trades $)$

\begin{tabular}{ccccc}
\hline & \multicolumn{4}{c}{ Trading Results (\%) } \\
\cline { 2 - 4 } & Annual Return & Annual std. dev. & Sharpe Ratio & Total Return \\
\hline Overnight-position Return Strategy & $-8.65 \%$ & $16.31 \%$ & -0.21 & $-156.90 \%$ \\
Daytime-position Return Strategy & $4.09 \%$ & $10.93 \%$ & 0.91 & $32.55 \%$ \\
\hline
\end{tabular}

\subsection{Comparative Return Analysis}

A comparative return analysis of 3x leveraged UWTI and 1x leveraged SPY, if it is temporaly (daily, annualy, total period) parameterized, indicates that the SPY 1x instrument has had better performance annualy under the introduced temporal Trend-reversal Anomaly in case of daytime-positions; whilst the UWTI 3x instrument achives better results under the introduced temporal Momentum Anomaly in case of overnight-positions.

This is because of the well-known in "Wall Street" 3x leveraged paradox, i.e. both (long) leveraged and (short) inverse-leveraged 3x instruments (ETF/ETN), of the same underline asset or index, in the long term always decline in price.

\subsection{Trade Performance Analysis}

Tables 3, 4 and 5 present the trade performance analysis results after applying the backtesting procedure on both instruments (UWTI and SPY). For statistical backtesting purposes, a capital of $\$ 100,000$ has been invested per trade and a commission cost of $\$ 0.01$ is regarded. This commission cost of $\$ 0.01$ per traded share results on significant (net) profit as shown in Tables 3 and 4.

Please note that in case of a commission cost of $\$ 0.02$ per share, the total net profit of both overnight-position and daytime-position return strategies would be less than zero. Even worst, if we add any slippage cost in overnight return strategy. But, thanks to internet-based low-cost brokerage nowadays available, commission cost is very low (\$0.005) and slippage cost is not applicable nowadays (Vayanos \& Woolley, 2013).

Following, Table 3 presents the perforance, in case of an overnight-position return strategy, of the introduced in the current article both market anomalies: the temporal Momentum Anomaly and the temporal Trend-reversal Anomaly.

Table 3. Overnight-position strategy: UWTI 3x leveraged ETN \& SPY 1x leveraged ETF: Trade performance analysis from backtesting data ( $\$ 100,000$ invested per trade; Total period: $1 / 1 / 2010-30 / 6 / 2016)$

\begin{tabular}{ccccccc}
\hline & Instrument & $\begin{array}{c}\text { Total number } \\
\text { of trades }\end{array}$ & $\begin{array}{c}\text { Winner } \\
\text { trades }\end{array}$ & $\begin{array}{c}\text { Loser } \\
\text { trades }\end{array}$ & $\begin{array}{c}\text { Profit without } \\
\text { commission cost }\end{array}$ & $\begin{array}{c}\text { Net Profit with commission } \\
\text { cost } \$ 0.01 \text { per share }\end{array}$ \\
\hline Temporal Momentum Anomaly & UWTI & 4,820 & 2,730 & 2,090 & $\$ 130,420$ & $\$ 4966$ \\
Temporal Trend-reversal Anomaly & SPY & 4,624 & 1,850 & 2,774 & $\$-156,900$ & $\$-234,370$ \\
\hline
\end{tabular}

Overnight or After-Hours trading (AHT) refers to the buying (selling) of securities on major exchanges outside of the regular trading hours. Both, the New York Stock Exchange (NYSE) and the Nasdaq National Market (NASDAQ), operate from 09:30 am to 04:00 pm Eastern Time. At one time limited to institutional investors and individual investors with high net worth, AHT is now an option for the average investor as well (Chemmanur, $\mathrm{He}, \& \mathrm{Hu}, 2009)$. 
The emergence of the Internet-based trading allows individual investors to interact electronically, but also lets large institutional investors interact anonymously, thereby hiding their actions. The development of AHT offers investors the possibility of great gains, but they should also be aware of some of its inherent risks and dangers:

- Less liquidity - There are far more buyers and sellers during regular hours. During AHT there may be less trading volume and it may be harder to convert shares to cash.

- Wide spreads - A lower volume in trading may result in a wide spread between bid and ask prices. Therefore, it may be hard for an individual to have his or her order executed at a favorable price.

- Small fish - While individual investors now have the opportunity to trade in an after-hours market, the reality is that they must compete against large institutional investors that have access to more resources than the average individual investor.

- Volatility - The AHT market is thinly traded in comparison to regular-hours trading. Therefore, the likelihood to experience severe price fluctuations in AHT than trading during regular hours is much high.

Following, Table 4 presents, after appling a backtesting procedure, the mean annual return of both introduced anomalies (temporal Momentum Anomaly and temporal Trend-reversal Anomaly) for the overnight AHT trade session splited in four time-periods: (a) 04:00 pm - 08:00 pm EST; (b) 08:00 pm - 06:00 am EST; (c) 06:00 am - 09:00 am EST; and 09:00 am - 09:30 am EST.

Table 4. Detailed overnight-position strategy: UWTI 3x leveraged ETN \& SPY 1x leveraged ETF: Trade performance analysis from backtesting data $(\$ 100,000$ invested per trade per annual; period: $1 / 1 / 2010-30 / 6 / 2016)$

\begin{tabular}{|c|c|c|c|c|c|c|}
\hline & \multicolumn{4}{|c|}{ Pre-market Back-testing } & \multicolumn{2}{|c|}{ Post-market Back-testing } \\
\hline & $\begin{array}{c}\text { Total } \\
\text { number of } \\
\text { trades } \\
\end{array}$ & $\begin{array}{c}\text { Intraday } \\
\text { Time-period }\end{array}$ & $\begin{array}{l}\text { Mean Annual Return (Net } \\
\text { Profit) with commission cost } \\
\$ 0.01 \text { per share }\end{array}$ & $\begin{array}{c}\text { Total } \\
\text { number of } \\
\text { trades } \\
\end{array}$ & $\begin{array}{c}\text { Intraday } \\
\text { Time-period }\end{array}$ & $\begin{array}{c}\text { Mean Annual Return (Net } \\
\text { Profit) with commission } \\
\text { cost } \$ 0.01 \text { per share } \\
\end{array}$ \\
\hline $\begin{array}{c}\text { Temporal Momentum } \\
\text { Anomaly (UWTI) }\end{array}$ & 1,205 & $\begin{array}{c}\text { 06:00 am - } \\
\text { 09:00 am EST }\end{array}$ & $\$ 1,877$ & 1,205 & $\begin{array}{c}\text { 04:00 pm - } \\
\text { 08:00 pm EST }\end{array}$ & $\$ 1,903$ \\
\hline $\begin{array}{l}\text { Temporal Momentum } \\
\text { Anomaly (UWTI) }\end{array}$ & 1,205 & $\begin{array}{c}\text { 09:00 am - } \\
\text { 09:30 am EST }\end{array}$ & $\$ 2,090$ & 1,205 & $\begin{array}{c}\text { 08:00 pm - } \\
\text { 06:00 am EST }\end{array}$ & $\$ 2,010$ \\
\hline $\begin{array}{l}\text { Temporal Trend-reversal } \\
\text { Anomaly (SPY) }\end{array}$ & 1,156 & $\begin{array}{c}\text { 06:00 am - } \\
\text { 09:00 am EST }\end{array}$ & $\$-2,090$ & 1,156 & $\begin{array}{c}\text { 04:00 pm - } \\
\text { 08:00 pm EST }\end{array}$ & $\$-2,326$ \\
\hline $\begin{array}{c}\text { Temporal Trend-reversal } \\
\text { Anomaly (SPY) }\end{array}$ & 1,156 & $\begin{array}{c}\text { 09:00 am - } \\
\text { 09:30 am EST }\end{array}$ & $\$-2,302$ & 1,156 & $\begin{array}{c}\text { 08:00 } \mathrm{pm}- \\
\text { 06:00 am EST }\end{array}$ & $\$-1,932$ \\
\hline
\end{tabular}

Following, Table 5 presents the total perforance, in case of a daytime-position return strategy, of the introduced in the current article both market anomalies: temporal Momentum Anomaly and temporal Trend-reversal Anomaly.

Table 5. Daytime-position strategy: UWTI 3x leveraged ETN \& SPY 1x leveraged ETF: Trade performance analysis from backtesting data ( $\$ 100,000$ invested per trade; Total period: 1/1/2010-30/6/2016)

\begin{tabular}{ccccccc}
\hline & Instrument & $\begin{array}{c}\text { Total number } \\
\text { of trades }\end{array}$ & $\begin{array}{c}\text { Winner } \\
\text { trades }\end{array}$ & $\begin{array}{c}\text { Loser } \\
\text { trades }\end{array}$ & $\begin{array}{c}\text { Profit without } \\
\text { commission cost }\end{array}$ & $\begin{array}{c}\text { Net Profit with commission } \\
\text { cost } \$ 0.01 \text { per share }\end{array}$ \\
\hline Temporal Momentum Anomaly & UWTI & 4,820 & 2,080 & 2,740 & $\$-67,310$ & $\$-148,064$ \\
Temporal Trend-reversal Anomaly & SPY & 4,624 & 2,541 & 2,083 & $\$ 32,550$ & $\$-44,920$ \\
\hline
\end{tabular}

For a number of twenty eight (28) 2x leveraged ETF/ETN backtested (1/1/2010-30/6/2016 data) both on a momentum anomaly and a trend-reversal anomaly based trading strategy, we found that $2 \mathrm{x}$ instruments belonged to Financial and Pharma-Medical Sectors perform better if applied a temporal Momentum Anomaly based trading strategy (Table 6).

On the other hand, 2x instruments belonged to Silver Miners, China, Emerging Markets, and Small Cap Sectors perform better if applied a temporal Trend-reversal Anomaly based trading strategy. In these cases, the Silver Miners Sector displays the biggest negative correlation (correlation coefficient) between these two anomalies (trading strategies returns) because of the complicated ETF structure involved (silver miners index; physical spot silver; silver CfD: XAG/USD) (Table 6). 
Also, for the Cyber Security \& IT, VIX, S\&P 500, NASDAQ 100, Treasury, Currency, and Yield Sectors no significant differences between momentum and trend-reversal had been notated. In these cases, the Treasury and Yield Sectors display the biggest positive correlation (correlation coefficient) between the paper's proposed two anomalies (trading strategies returns) because of the conservative ETF structure involved (Table 6) (Lee \& Ni, 2002; Kilian, 2009).

Table 6. $2 \mathrm{x}$ leveraged instruments: Performance difference \& autocorrelation between momentum \& trend-reversal temporal anomalies

\begin{tabular}{|c|c|c|c|c|c|c|}
\hline \multicolumn{3}{|c|}{$\begin{array}{l}\text { The 2x Leveraged Instruments } \\
\text { (ETF/ETN; Equity Funds; Fixed } \\
\text { Income Funds) }\end{array}$} & \multirow{2}{*}{$\begin{array}{c}\text { Momentum Anomaly } \\
\text { Annual Return (\$) } \\
\text { (on average) }\end{array}$} & \multirow{2}{*}{ 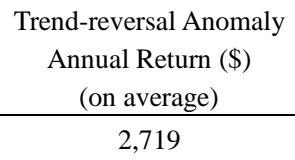 } & \multirow{2}{*}{$\begin{array}{c}\text { Difference between } \\
\text { Momentum \& } \\
\text { Trend-reversal (\$) }\end{array}$} & \multirow{2}{*}{$\begin{array}{c}\text { Autocorrelation } \\
\text { between Momentum \& } \\
\text { Trend-reversal } \\
+0.015\end{array}$} \\
\hline 1 & CWEB & ChinaInternet & & & & \\
\hline 2 & CHAU & China CSI 300 & $-10,200$ & 3,032 & $-13,232$ & +0.014 \\
\hline 3 & DXHLX & China Monthly & $-14,283$ & 1,662 & $-15,945$ & +0.015 \\
\hline 4 & HAKK & Security \& IT & 15,533 & 16,021 & -488 & -0.003 \\
\hline 5 & HAKD & Security \& IT & 12,281 & 12,833 & -552 & -0.005 \\
\hline 6 & PILL & Pharrma-Medical & $-7,704$ & $-9,901$ & 2,197 & +0.002 \\
\hline 7 & PILS & Pharma-Medical & $-7,033$ & $-9,622$ & 2,589 & +0.003 \\
\hline 8 & SHNY & Silver Miners & $-40,077$ & $-22,910$ & $-17,167$ & -0.209 \\
\hline 9 & DULL & Silver Miners & $-37,435$ & $-23,732$ & $-13,703$ & -0.174 \\
\hline 10 & TVIX & VIX Short-term & 1,032 & 1,077 & -45 & +0.001 \\
\hline 11 & TVIZ & VIX Long-term & 1,264 & 1,192 & 72 & +0.001 \\
\hline 12 & DXSLX & S\&P 500 & 3,642 & 3,843 & -201 & +0.023 \\
\hline 13 & DXSSX & S\&P 500 & 4,120 & 4,424 & -304 & +0.022 \\
\hline 14 & SPUU & S\&P 500 & 4,692 & 4,873 & -181 & +0.023 \\
\hline 15 & DXQLX & NASDAQ 100 & 7,922 & 8,933 & $-1,011$ & +0.031 \\
\hline 16 & DXNLX & NASDAQ 100 & 7,327 & 8,502 & $-1,175$ & +0.033 \\
\hline 17 & DXRLX & Small Cap & $-9,065$ & $-2,022$ & $-7,043$ & -0.076 \\
\hline 18 & DXRSX & Small Cap & $-13,534$ & $-4,772$ & $-8,762$ & -0.076 \\
\hline 19 & DXELX & Emerging Mrkts & $-9,488$ & $-2,902$ & $-6,586$ & -0.089 \\
\hline 20 & BRZU & Emerging Mrkts & $-13,444$ & $-3,244$ & $-10,200$ & -0.095 \\
\hline 21 & DXKLX & Treasury & 2,304 & 2,893 & -589 & +0.305 \\
\hline 22 & DXKSX & Treasury & 4,055 & 4,070 & -15 & +0.338 \\
\hline 23 & HEGE & Currency & 3,711 & 4,721 & $-1,010$ & -0.002 \\
\hline 24 & HEGJ & Currency & 3,053 & 3,595 & -542 & -0.001 \\
\hline 25 & DXHYX & Yield & 2,044 & 2,744 & -700 & +0.292 \\
\hline 26 & HYDD & Yield & 2,831 & 2,904 & -73 & +0.320 \\
\hline 27 & EUFL & Financial & 9,230 & 4,921 & 4,309 & +0.205 \\
\hline 28 & RETL & Financial & 10,233 & 5,103 & 5,130 & +0.224 \\
\hline
\end{tabular}

Note. Performance analysis from backtesting data ( $\$ 100,000$ invested per trade; Total period: 1/1/2010-30/6/2016). The instruments were selected from Direxion Investments (Note 1) and Velocity Shares (Note 2) portfolio.

We have back-tested and projected the above $282 \mathrm{x}$ leveraged ETF/ETN instruments into the proposed two temporal anomalies approaches as both daytime (intraday) and overnight trading strategies; and document significant "time series momentum" in equity index, currency, commodity, and bond futures for each of these 28 instruments we consider.

Thereafter, we find for specific U.S. market Sectors:

(i) A 5-year persistence in positive overnight-position returns for the temporal Momentum anomaly approach (applied to: Financial Sector, and Pharma-Medical Sector); and

(ii) A 5-year persistence in positive daytime-position returns for the temporal Trend-reversal anomaly approach (applied to: Silver Miners Sector, China Sector, Emerging Markets Sector, and Small Cap Sector).

Please note that, these 5-year persistence partially reverses over longer horizons (e.g. a 10-year period), and this perseverance is consistent with classical sentiment theories of initial under-reaction and delayed over-reaction. 
For a number of twenty eight (28) 3x leveraged ETF/ETN backtested (1/1/2010-30/6/2016 data) both on a momentum anomaly and a trend-reversal anomaly based trading strategy, we found that $3 \mathrm{x}$ instruments belonged to Semiconductor, Natural Gas, and Healthcare Sectors perform better if applied a temporal Momentum Anomaly based trading strategy (Table 7).

On the other hand, 3x instruments belonged to Gold Miners, Biotech, Crude (Americal) Oil, Emerging Markets, and Technology Sectors perform better if applied a temporal Trend-reversal Anomaly based trading strategy. In these cases, the Gold Miners Sector displays the biggest negative correlation (correlation coefficient) between these two anomalies (trading strategies returns) because of the complicated ETF structure involved (gold miners index; physical spot gold; gold cfd: XAU/USD) (Table 7).

Also, for the Energy, Financial, and Real Estate Sectors no significant differences between momentum and trend-reversal had been notated. In these cases, the Financial Sector displays the biggest positive correlation (correlation coefficient) between the paper's proposed two anomalies (trading strategies returns) because of the conservative ETF structure involved (Table 7).

Table 7. 3x leveraged instruments: Performance difference \& autocorrelation between momentum \& trend-reversal temporal anomalies

\begin{tabular}{|c|c|c|c|c|c|c|}
\hline \multicolumn{3}{|c|}{$\begin{array}{c}\text { The 3x Leveraged Instruments } \\
\text { (ETF/ETN; Natural Gas CfD; Crude } \\
\text { Oil CfD; Gold GC CfD) }\end{array}$} & \multirow{2}{*}{$\begin{array}{c}\text { Momentum Anomaly } \\
\text { Annual Return (\$) } \\
\text { (on average) }\end{array}$} & \multirow{2}{*}{$\begin{array}{c}\text { Trend-reversal Anomaly } \\
\text { Annual Return (\$) } \\
\text { (on average) }\end{array}$} & \multirow{2}{*}{$\begin{array}{c}\text { Difference between } \\
\text { Momentum \& } \\
\text { Trend-reversal }(\$)\end{array}$} & \multirow{2}{*}{$\begin{array}{c}\begin{array}{c}\text { Autocorrelation between } \\
\text { Momentum \& } \\
\text { Trend-reversal }\end{array} \\
-0.002\end{array}$} \\
\hline 1 & GUSH & Energy & & & & \\
\hline 2 & DRIP & Energy & $-29,214$ & $-32,371$ & 3,157 & -0.003 \\
\hline 3 & ERX & Energy & $-16,772$ & $-19,090$ & 2,318 & -0.003 \\
\hline 4 & ERY & Energy & $-22,021$ & $-23,441$ & 1,420 & -0.002 \\
\hline 5 & GASL & Natural Gas & $--20,005$ & $-25,902$ & 5,897 & +0.011 \\
\hline 6 & GASX & Natural Gas & $-19,321$ & $-21,522$ & 2,201 & +0.013 \\
\hline 7 & UGAZ & Natural Gas & $-16,329$ & $-18,906$ & 2,577 & +0.009 \\
\hline 8 & DGAZ & Natural Gas & $-15,076$ & $-16,210$ & 1,134 & +0.006 \\
\hline 9 & UWTI & Crude Oil & 13,882 & 17,805 & $-3,923$ & +0.022 \\
\hline 10 & DWTI & Crude Oil & 10,022 & 17,033 & $-7,011$ & +0.027 \\
\hline 11 & $\mathrm{LABU}$ & Biotech & 11,906 & 19,520 & $-7,614$ & -0.002 \\
\hline 12 & LABD & Biotech & 14,845 & 27,401 & $-12,556$ & -0.002 \\
\hline 13 & NUGT & Gold Miners & $-62,002$ & $-12,649$ & $-49,353$ & -0.287 \\
\hline 14 & DUST & Gold Miners & $-60,798$ & $-17,040$ & $-43,758$ & -0.293 \\
\hline 15 & JNUG & Gold Miners & $-71,053$ & $-20,339$ & $-50,714$ & -0.275 \\
\hline 16 & JDST & Gold Miners & $-69,342$ & $-22,521$ & $-46,821$ & -0.288 \\
\hline 17 & FAS & Financial & 8,622 & 7,509 & 1,113 & +0.204 \\
\hline 18 & FAZ & Financial & 8,903 & 7,772 & 1,131 & +0.208 \\
\hline 19 & EDC & Emerging Mrkt & $-15,006$ & $-9,901$ & $-5,105$ & -0.103 \\
\hline 20 & EDZ & Emerging Mrkt & $-17,807$ & $-13,603$ & $-4,204$ & -0.107 \\
\hline 21 & SOXL & Semiconductor & 32,922 & 19,033 & 13,889 & -0.004 \\
\hline 22 & SOXS & Semiconductor & 12,634 & 9,409 & 3,225 & -0.006 \\
\hline 23 & TECL & Technology & 25,021 & 29,322 & $-4,301$ & -0.003 \\
\hline 24 & TECS & Technology & 12,807 & 15,671 & $-2,864$ & -0.003 \\
\hline 25 & CURE & Healthcare & $-9,027$ & $-12,529$ & 3,502 & +0.002 \\
\hline 26 & SICK & Healthcare & $-8,320$ & $-12,638$ & 4,318 & +0.003 \\
\hline 27 & DRN & Real Estate & $-7,301$ & $-6,048$ & $-1,253$ & +0.005 \\
\hline 28 & DRV & Real Estate & $-19,736$ & $-18,724$ & $-1,012$ & +0.008 \\
\hline
\end{tabular}

Note. Performance analysis from backtesting data $(\$ 100,000$ invested per trade; Total period: 1/1/2010 - 30/6/2016). The instruments were selected from Direxion Investments (2017) and Velocity Shares (2017) portfolio.

\section{Conclusions \& Discussion}

Over the years, many studies have presented data about what academics call "market anomalies". Typically, for these anomalies, there are three common classifications: Fundamental, Technical, and Calendar-based anomalies. Also, there is another class of anomalies that simply could be referred to as "temporal" because of the time-series (timing) functionality involved. In this article we have discussed two of these "temporal" anomalies, 
called the temporal Momentum market anomaly and the temporal Trend-reversal market anomaly.

These anomalies could be characterized as trading strategy approaches rather than as documented trading strategies; but if they parameterized by the time and particular by the overnight and intraday time periods, then they would respected as time-series temporal trading strategies.

Price action is more efficient and therefore more information and trading functionality is revealed per time during the intraday (daytime) session than after-hours (overnight). However, the after-hours overnight low trading volume generates great volatility and therefore significant trading opportunities (albeit inefficient) appear and offer excellent chances for price action analysis and opportunities for the introduced in this paper two temporal market anomalies.

The main achievement of this paper was the introduction of two new anomalies, the temporal Momentum Market Anomaly and the temporal Trend-reversal Market Anomaly, armed both with innovative functionalities relating to "psychological time" at the beginning of a move (Livermore, 1940/2001) during the daytime and the overnight trading sessions. For instance, a discussed functionality was: "buy a bullish $3 \mathrm{x}$ instrument at the last 5 min before the closing bell - hold position overnight - sell this position next day during the morning session".

As an application domain we choose the SEC-approved (U.S. Securities and Exchange Commission; SEC.gov) category of leveraged "instruments" for mom-and-pop investors. Actually, they are neither stocks nor mutual funds; they're just packaged products -of an underlined asset (e.g. WTI ETN, Gold miners ETF)- using derivatives to create daily leverage. So, we have back-tested, in an application domain of twenty-eight (28) $2 x$ leveraged ETF/ETN and twenty-eight (28) 3x leveraged ETF/ETN instruments, the proposed temporal anomalies approaches as daytime (intraday) and overnight trading strategies and document significant "time-series momentum" in equity, currency, commodity, and futures for each of the fifty-six (56) instruments we consider.

We find for specific U.S. market Sectors: (i) a 5-year persistence in positive overnight-position returns for the temporal momentum anomaly approach; and (ii) a 5-year persistence in positive daytime-position returns for the temporal trend-reversal anomaly approach. This 5-year persistence partially reverses over longer horizons, consistently with the sentimental and emotional theories of initial under-reaction and delayed over-reaction.

Obviously, according to classical financial theories, a diversified portfolio of trading strategies based on the introduced temporal momentum and temporal trend-reversal anomalies -for a number of asset classes and market Sectors- delivers substantial abnormal returns with little exposure to standard asset pricing factors and performs best during extreme markets. Examining the trading activities of position shareholders, swing traders, speculators and hedgers, we found that overnight-position speculators profit from the proposed temporal momentum trading strategy approach at the expense of hedgers, and daytime swing traders profit from the proposed temporal trend-reversal trading strategy approach at the expense of position long-term shareholders.

Individual trades contain more information and trading TTF functionality after-hours (overnight) than during the daily session (intraday: 09:30-16:00). Hence, because the information asymmetry declines over the intraday trading hours, price changes are larger, reflect more private information and trading functionality, and they are less noisy before the open than after the bell-clock. The proposed approaches have volatility-strategy and volatility-tactical functionality, and they can be used in concert with ETFs, ETNs, swaps, futures, and/or options to implement risk management strategies and it is dedicated to providing individual traders and institutional investors with sophisticated solutions for portfolio and trading risk management. The proposal's success results from delivering innovative, efficient, and intelligent functionality for a wide range of intraday speculators and swing traders.

Paper contributes to corporate finance literature by: (a) the introduction of the new market inefficiency category named "temporal market anomalies"; (b) the introduction, definition, analysis and documentation of the innovative terms "the temporal momentum market anomaly" and "the temporal trend-reversal market anomaly" as timing market anomalies; (c) the parameterizing of both new market anomalies with temporal trading strategies variables, like overnight-position (4 different time periods has been examined) and daytime-position trading; (d) the comparative analysis of the executive application (a back-testing case study) of these new terms in two instruments, one 3x leveraged ETN and another 1x leveraged ETF; and (e) the comparative analysis of the executive application (a back-testing case study) of these new terms in 56 instruments (28 3x leveraged ETF/ETN and 28 2x leveraged ETF/ETN).

The trade performance analysis applied on these instruments demonstrated that, in a nowadays internet-based trading with very low commission cost and none slippage cost, (i) a well designed overnight-position return strategy (preferable for the natural gas and crude oil instruments - Energy Sector) based on temporal momentum 
anomaly; and (ii) a well designed intraday-position return strategy (preferable for the junior gold miners instruments - Gold Miners Sector) based on temporal trend-reversal anomaly, could gain benefit at the expense of positional investors in $3 \mathrm{x}$ instruments and intraday non-commercial speculators.

The temporal (time-series) momentum and trend-reversal trading approaches discussed in this paper represent some of the most direct tests of the random walk hypothesis and a number of prominent behavioral and rational asset pricing theories. Our findings present new evidence and challenges for those theories and for future research.

\section{Acknowledgments}

I would like to thank the anonymous reviewers for their careful reading of the manuscript and their many insightful comments and suggestions. Also, the financial support (covering mainly the CoT/CFTC, Zacks, and the Barron's \& WSJ.com market data expenses) from the EU/LLP Programme "EPOCHE 2014" (with Project No. 2013-1-GR1-ERA10-15376) is gratefully acknowledged.

\section{Conflicts of Interest}

The author has not declared any conflict of interest with the companies and market quotes appeared on this article. Also, on writing and publishing this paper she has no position in any stocks, ETF, ETN and trading instruments mentioned.

\section{Disclaimer}

The approaches and trading strategies provided on this article are general information services for the public. The author is not an investment advisor, and she does not endorse or recommend any securities or other investments. Market quotes and certain other information on this article, as well as reference materials or links to sites, have been compiled unbiased from publicly available sources believed to be reliable and are for general informational and research purposes only. The accuracy or completeness of the information, approaches, plans and trading strategies contained herein is not guaranteed and is not intended to be relied upon for investment purposes.

\section{References}

Ahn, D. H., Conrad, J., Dittmar, R. F. (2003). Risk adjustment and trading strategies. The Review of Financial Studies, 16, 459-485. http://dx.doi.org/ 10.1093/rfs/hhg001

Alti, A., \& Sulaeman, J. (2012). When do high stock returns Trigger Equity Issues? Journal of Financial Economics, 103, 61-87. http://dx.doi.org/10.1016/j.jfineco.2011.08.007

Ang, A., Hodrick, R. J., Xing, Y., \& Zhang, X. (2006). The Cross-Section of Volatility and Expected Returns. Journal of Finance, 61, 259-299. Retrieved from http://web.ics.purdue.edu/ zhang654/jf2006.pdf

Asness, C. (1994). Variables that Explain Stock Returns (Unpublished Ph.D. Dissertation). The University of Chicago. Retrieved from the Online Computer Library Center global cooperative/WorldCat union catalog. http://www.worldcat.org/title/variables-that-explain-stock-returns-simulated-and-empirical-evidence/oclc/3 83860488

Asness, C., Moskowitz, T. J., \& Pedersen, L. H. (2016). Value and Momentum Everywhere: Factors, Monthly. AQR Capital Management, The University of Chicago, and The National Bureau of Economic Research. Retrieved from https://www.aqr.com/library/data-sets/value-and-momentum-everywhere-factors-monthly

Asness, C., Moskowitz, T. J., Pedersen, L. H. (2013). Value and Momentum Everywhere. The Journal of Finance, LXVIII(3), 929-985. http://dx.doi.org/10.1111/jofi.12021

Baker, M., Stein, J. C., \& Wurgler, J. (2003). When does the Market Matter? Stock Prices and the Investment of Equity-dependent Firms. The Quarterly Journal of Economics, 118, 969-1005. http://dx.doi.org/10.1162/00335530360698478

Bali, T. G., \& Cakici, N. (2008). Idiosyncratic Volatility and the Cross Section of Expected Stock Returns. Journal of Financial and Quantitative Analysis 43, 29-58. Retrieved from http://citeseerx.ist.psu.edu/viewdoc/download?doi=10.1.1.468.6852\&rep=rep1\&type=pdf

Barclay, M. J., \& Hendershott, T. (2003). Price Discovery and Trading After Hours. The Review of Financial Studies, 16(4), 1041-1073. http://dx.doi.org/10.1093/rfs/hhg030

Barron's Financial Investment News and Market Data. (2016). Retrieved from http://www.barrons.com/data; and http://www.wsj.com; and http://www.wsj.com/europe 
Basdekidou, V. A. (2015). Functionality, Returns and Efficiency before and after the Debt Crisis: An Empirical Analysis of the Greek Stock Market (Unpublished doctoral dissertation). Bulgarian Academy of Sciences -Economic Research Institute, Bulgaria.

Basdekidou, V. A. (2016a). IPO Trading with Short-term and Intraday Temporal Functionalities. Business and Economics Journal, 7(4). http://dx.doi.org/10.4172/2151-6219.1000257

Basdekidou, V. A. (2016b). Personalized Temporal Trading Functionalities Engaged in Calendar Market Anomalies: Empirical Evidences from the 2007 and 2009 Financial Crises. Journal of Business \& Financial Affairs, 5(4). http://dx.doi.org/10.4172/2167-0234.1000225

Basdekidou, V. A. (2017a). Seasoned Equity Offerings as Technical Market Anomalies: Long-Term Temporal Trading Functionalities. International Journal of Economics and Finance, 9(1), 96-105. http://dx.doi.org/10.5539/ijef.v9n1p96

Basdekidou, V. A. (2017b). The Overnight Return Temporal Market Anomaly. International Journal of Economics and Finance, 9(3), 1-10. http://dx.doi.org/10.5539/ijef.v9n3p1

Basdekidou, V. A., \& Styliadou, A. A. (2017). Technical Market Anomalies: Leveraged ETF Trading with Daily and Intraday Temporal Functionalities. Business and Economics Journal, 8(1). http://dx.doi.org/10.4172/2151-6219.1000275

Campbell, J. Y., Giglio, S., Polk, C., \& Turley, R. (2014). An Intertemporal CAPM with Stochastic Volatility. London School of Economics and Political Siences working paper, LSE London, UK. Retrieved from https://pdfs.semanticscholar.org/0044/748cabfc0ee3f7fdeea1992ce8efd7aaaa5f.pdf

Cesari, A. D., Espenlaub, S., Khurshed, A., \& Simkovic, M. (2012). The Effects of Ownership and Stock Liquidity on the Timing of Repurchase Transactions. Journal of Corporate Finance, 18, 1023-1050. http://dx.doi.org/10.1016/j.jcorpfin.2012.06.004

Chemmanur, T. J., He, S., \& Hu, G. (2009). The role of Iinstitutional Investors in Seasoned Equity Offerings. Journal of Financial Economics, 94, 384-411. http://dx.doi.org/10.1016/j.jfineco.2008.12.011

Chen, X., Harford, J., \& Li, K. (2007). Monitoring: Which institutions matter? Journal of Financial Economics, 86, 279-305. http://dx.doi.org/10.1016/j.jfineco.2006.09.005

De Bondt, W. F. M., \& Thaler, R. (1985). Does the Stock Market Overreact? The Journal of Finance, 40(3), 793-805. http://dx.doi.org/10.2307/2327804

Direxion Investments (2017). Retrieved from http://www.direxioninvestments.com/

Edelen, R. M., Ince, O., \& Kadlec, G. B. (2015). Institutional Investors and Stock Return Anomalies. E- Journal SSRN. http://dx.doi.org/10.2139/ssrn.2359744

Gibson, S., Safieddine, A., \& Sonti, R. (2004). Smart investments by smart money: Evidence from seasoned $\begin{array}{lllll}\text { equity offerings. Journal of Financial Economics, } & \text { 72, }\end{array}$ http://dx.doi.org/10.1016/j.jfineco.2003.05.001

Hao, G. Q. (2014). Institutional shareholder investment horizons and seasoned equity offerings. Financial Management, 43, 87-111. http://dx.doi.org/10.1111/fima.12038

Jegadeesh, N., \& Titman, S. (1993). Returns to Buying Winners and Selling Losers: Implications for Stock Market Efficiency. The Journal of Finance, 48(1), 65-91. http://dx.doi.org/10.2307/2328882

Kang, W., Ratti, R. A., \& Vespignani, J. (2016). The impact of oil price shocks on the U.S. stock market: A note on the roles of U.S. and non-U.S. oil production. Economics Letters 145, 176-181. http://dx.doi.org/10.1016/j.econlet.2016.06.008

Kilian, L. (2009). Not all oil price shocks are alike: Disentangling demand and supply shocks in the crude oil market. American Economic Review, 99(3), 1053-1069. http://dx.doi.org/ 10.1257/aer.99.3.1053

Lee, K., \& Ni, S. (2002). On the dynamic effects of oil price shocks: A study using industry level data. Journal of Monetary Economy, 49, 823-852. http://dx.doi.org/10.1016/S0304-3932(02)00114-9

Lefèvre, E. (2010). Reminiscences of a Stock Operator (p. 423). Hoboken, NJ: John Wiley \& Sons, Inc.

Livermore, J. (2001). How to Trade in Stocks (p. 179, R. Smitten, Translation). New York, NY: McGraw-Hill.

Lou, D., Polk, C., \& Skouras, S. (2016). A Tug of War: Overnight versus Intraday Expected Returns. London School of Economics and Political Sciences working paper, LSE London, UK. Retrieved from 
http://personal.lse.ac.uk/loud/overnightmom.pdf

Malkiel, B. G. (2003). A Random Walk Down Wall Street (p. 463). New York, NY: W. W. Norton \& Company. Retrieved from http:// http://site.iugaza.edu.ps/wdaya/files/2013/

Markoulis, S. N., \& Neofytou, N. (2016). An Empirical Analysis of the Relationship between Oil Prices and Stock Markets. International Journal of Economics and Finance, 8(12), 120-131. http://dx.doi.org/10.5539/ijef.v8n12p120

Moskowitz, T. J., Ooi, Y. H., \& Pedersen, L. H. (2012). Time series momentum. Journal of Financial Economics, 104, 228-250. http://dx.doi.org/ 10.1016/j.jfineco.2011.11.003

Nguyen, X. M., \& Tran, Q. T. (2016). Dividend Smoothing and Signaling Under the Impact of the Global Financial Crisis: A Comparison of US and Southeast Asian Markets. International Journal of Economics and Finance, 8(11), 118-123. http://dx.doi.org/10.5539/ijef.v8n11p118

Nickerson, D. (2016). Asset Price Volatility, Credit Rationing and Rational Lending Discimination. International Journal of Economics and Finance, 8(10), 140-158. http://dx.doi.org/10.5539/ijef.v8n10p140

Ogden, J. P., \& Wu, S. (2013). Reassessing the Effect of Growth Options on Leverage. Journal of Corporate Finance, 23, 182-195. http://dx.doi.org/10.1016/j.jcorpfin.2013.08.008

Skyba, E. (2012). The Overnight Return Study. Stocks \& Commodities, 30(2), 34-38. Retrieved from $\mathrm{http} / / /$ technical.traders.com/archive/articlefinal.asp?file=IV30\C02\241SKYB.pdf

Styliadis, A. D. (2007). E-learning Documentation of Historical Living Systems with 3-d Modeling Functionality. Informatica, 18(3), 419-446. Retrieved from http://www.mii.vu.lt/informatica/pdf/INFO686.pdf

Styliadis, A. D., \& Vassilakopoulos, M. G. (2005). A Spatio-Temporal Geometry-based Model for Digital Documentation of Historical Living Systems. Information \& Management, 42(2), 349-359. http://dx.doi.org/10.1016/j.im.2004.01.006

Vayanos, D., \& Woolley, P. (2013). An Institutional Theory of Momentum and Reversal. Review of Financial Studies, forthcoming. London School of Economics and Political Sciences working paper. LSE London, UK. Retrieved from http://personal.lse.ac.uk/vayanos/Papers/ITMR_RFS13.pdf

Velocity Shares (2017). Retrieved from http://www.velocitySharesETNs.com/

Wilder, W. J. Jr. (1978). New Concepts in Technical Trading Systems (p. 130). Winston-Salem \& Greensboro, NC: Trend Research. Library of Congress Card Catalog No. 78-60759. Retrieved from http://rls.bsd.com.br/ rls/Classicos/Welles\%20Wilder\%20-\%20New\%20Concepts\%20in\%20Technical\%20 Trading\%20Systems.pdf

\section{Notes}

Note 1. Direxion, a leader in daily trend-based instruments, builds products for investors who want more than the status quo. Their index-based ETF products deliver directional instruments, options, magnified exposure, momentum and trend-reversal strategies. The company has approximately $\$ 11$ billion in assets under management as of September 30, 2016. Direxion specializes in providing decisive investors with solutions that deliver the flexibility to position portfolios opportunistically. Founded in 1997, Direxion has offices in US and Hong Kong.

Note 2. Velocity Shares is a leader in designing exchange-traded products, trend and momentum instruments (ETF, ETN) and sophisticated volatility momentum and trend-reversal strategies for institutional investors. The team is focused on developing liquid instruments that enable institutional investors to manage their risk, generate additional yield and express short-term market views. The team has significant experience across asset classes on both the buy- and sell-sides of the financial markets.

\section{Copyrights}

Copyright for this article is retained by the author(s), with first publication rights granted to the journal.

This is an open-access article distributed under the terms and conditions of the Creative Commons Attribution license (http://creativecommons.org/licenses/by/4.0/). 